\title{
Enthalpic Barriers to the Hydrophobic Binding of Oligosaccharides to Phage P22 Tailspike Protein ${ }^{\dagger}$
}

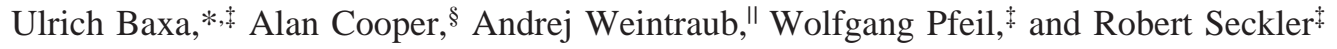 \\ Physikalische Biochemie, Universität Potsdam, Karl-Liebknecht-Strasse 24-25, D-14476 Golm, Germany, \\ Chemistry Department, Glasgow University, Glasgow G12 8QQ, U.K., and Karolinska Institute, Department of Immunology, \\ Microbiology, Pathology and Infectious Diseases, Division of Clinical Bacteriology, Huddinge University Hospital, \\ S-14186 Huddinge, Sweden
}

Received August 28, 2000; Revised Manuscript Received December 15, 2000

\begin{abstract}
The structural thermodynamics of the recognition of complex carbohydrates by proteins are not well understood. The recognition of $O$-antigen polysaccharide by phage P22 tailspike protein is a highly suitable model for advancing knowledge in this field. The binding to octa- and dodecasaccharides derived from Salmonella enteritidis $O$-antigen was studied by isothermal titration calorimetry and stoppedflow spectrofluorimetry. At room temperature, the binding reaction is enthalpically driven with an unfavorable change in entropy. A large change of $-1.8 \pm 0.2 \mathrm{~kJ} \mathrm{~mol}^{-1} \mathrm{~K}^{-1}$ in heat capacity suggests that the hydrophobic effect and water reorganization contribute substantially to complex formation. As expected from the large heat-capacity change, we found enthalpy-entropy compensation. The calorimetrically measured binding enthalpies were identical within error to van't Hoff enthalpies determined from fluorescence titrations. Binding kinetics were determined at temperatures ranging from 10 to $30^{\circ} \mathrm{C}$. The second-order association rate constant varied from $1 \times 10^{5} \mathrm{M}^{-1} \mathrm{~s}^{-1}$ for dodecasaccharide at $10{ }^{\circ} \mathrm{C}$ to $7 \times 10^{5} \mathrm{M}^{-1} \mathrm{~s}^{-1}$ for octasaccharide at $30^{\circ} \mathrm{C}$. The first-order dissociation rate constants ranged from 0.2 to $3.8 \mathrm{~s}^{-1}$. The Arrhenius activation energies were close to 50 and $100 \mathrm{~kJ} \mathrm{~mol}^{-1}$ for the association and dissociation reactions, respectively, indicating mainly enthalpic barriers. Despite the fact that this system is quite complex due to the flexibility of the saccharide, both the thermodynamic and kinetic data are compatible with a simple one-step binding model.
\end{abstract}

Carbohydrate-protein interactions play an important role in many biological recognition processes. Compared to protein-protein interactions $(1-4)$, the relation between structure and thermodynamics of carbohydrate binding is much less well understood, although there are some very well studied systems $(5-14)$ and although the concept of empirical parameters for calculating thermodynamic data from the change in accessible surface area has been applied here, too (14-16). Generally, most carbohydrate-protein interactions are enthalpically driven and opposed by an unfavorable change in entropy $(17,18)$. Most of the determined changes in heat capacity for these binding reactions with small oligosaccharides were small $(<0.5 \mathrm{~kJ}$ $\mathrm{mol}^{-1} \mathrm{~K}^{-1}$ ) and negative. Enthalpy-entropy compensation for different ligands to the same protein and even for totally different systems was described (17). This was mainly interpreted to be due to solvent reorganization (19). This and

$\dagger$ This work has been supported by grants from the Deutsche Forschungsgemeinschaft and the Fonds der Chemischen Industrie (U.B., R.S., and W.P.) and the UK Biotechnology and Biological Science Research Council and Engineering and Physical Sciences Research Council (A.C.).

* To whom correspondence should be addressed: Physikalische Biochemie, Universität Potsdam, Karl-Liebknecht-Str. 24-25, D-14476 Golm, Germany. Telephone: [+49] 331977 5243. Fax: [+49] 331 977 5062. E-mail: baxa@rz.uni-potsdam.de.

$\doteqdot$ Universität Potsdam.

$\S$ Glasgow University.

"Huddinge University Hospital. other results led to the conclusion that release of solvent molecules from polyamphiphilic surfaces can drive binding reactions not only by an increase in entropy (hydrophobic effect) but also by a decrease in enthalpy (20-23). Structural and solution data for binding of monosaccharides and small oligosaccharides to lectins and transport proteins indicate a somewhat higher number of hydrogen bonds and a higher binding enthalpy per contact surface than in protein folding and protein-protein complexes (15). Very little is known about binding of larger, more complex oligosaccharides to proteins, because only in some cases are both structural and thermodynamic data available. One such protein recognizing a large complex carbohydrate is the tailspike protein of Salmonella phage P22. Three to six homotrimers composed of $72 \mathrm{kDa}$ subunits must be attached to each phage to form infectious virus particles. The tailspikes bind the $O$-antigen polysaccharide of the host cells belonging to serotype A, B, or $\mathrm{D}_{1}$. Their $O$-antigens have the main chain trisaccharide repeating unit $\alpha$-D-mannose- $(1 \rightarrow 4)$ - $\alpha$-L-rhamnose- $(1 \rightarrow 3)-\alpha$ D-galactose- $(1 \rightarrow 2)$ in common, but differ in the 2,6-dideoxyhexose substituent at $\mathrm{C}-3$ of the mannose. The tailspike protein also has a hydrolyzing activity toward the $\alpha$-L-Rha$(1 \rightarrow 3)-\alpha-D-G a l$ glycosidic bond, producing tandem repeats (octasaccharide) as the main product. The endorhamnosidase activity is required for infectivity (U. Baxa, R. Seckler, C. Haase-Pettingell, and J. King, unpublished results), but its precise function in the infection cycle is not well understood. Binding and hydrolysis reactions have been characterized 

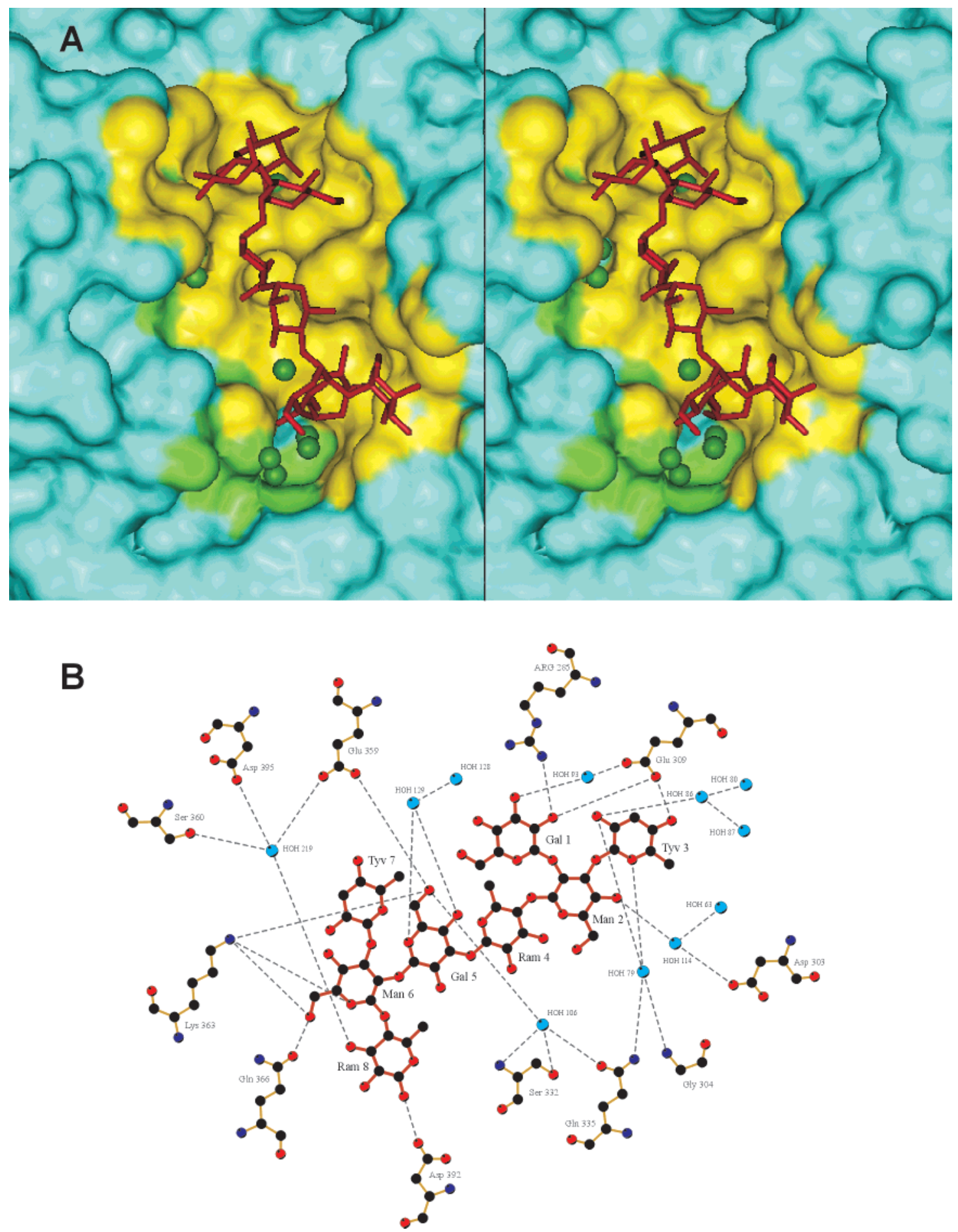

FIGURE 1: Binding site of TSP. (A) Stereoview of the octasaccharide binding site surface. Atoms directly contacting the saccharide are colored yellow, and atoms involved in water-mediated contacts are colored green. Atoms not involved in saccharide binding are colored cyan. Octasaccharide bonds are shown as red sticks. Water atoms having contacts to both the protein and the saccharide are shown as green balls. The figure was made using InsightII (Molecular Simulations, San Diego, CA). (B) Schematic representation of the hydrogen bonds between TSP and the octasaccharide. Atoms are shown as balls colored by the following code: carbon, black; nitrogen, dark blue; and oxygen, red. Water molecules are shown as light blue balls. Bonds between ligand atoms are red, and bonds of protein residues are yellow. The figure was made using LIGPLOT (63).

by fluorescence titration and with the help of fluorescencelabeled $O$-antigen fragments (24). The atomic structure of the $O$-antigen binding carboxy-terminal domain of TSP has been determined to a resolution of $1.56 \AA(25,26)$. The structure of the amino-terminal domain, the connection to the phage head, was determined separately (25). The main part of TSP is a right-handed parallel $\beta$-helix consisting of 13 turns. The carbohydrate binding site runs parallel to the helix axis flanked by a 63-residue domain and three smaller loops inserted in the $\beta$-helix (Figure 1). Crystal structures of complexes with oligosaccharide fragments from different $O$-antigen serogroups disclosed the largest interaction surfaces of carbohydrates liganded to proteins known to date $(25,27)$.

In the paper presented here, we investigate the thermodynamics of $\mathrm{O}$-antigen binding by isothermal calorimetry 


\begin{tabular}{|c|c|c|c|c|c|c|c|}
\hline & $T\left({ }^{\circ} \mathrm{C}\right)$ & $n^{b}$ & $\begin{array}{c}K_{\mathrm{D}}^{b} \\
(\mu \mathrm{M})\end{array}$ & $\begin{array}{c}-\Delta G^{\circ a} \\
\left(\mathrm{~kJ} \mathrm{~mol}^{-1}\right)\end{array}$ & $\begin{array}{c}-\Delta H^{\circ b} \\
\left(\mathrm{~kJ} \mathrm{~mol}^{-1}\right)\end{array}$ & $\begin{array}{c}-T \Delta S^{\circ} \\
\left(\mathrm{kJ} \mathrm{mol}^{-1}\right)\end{array}$ & $\begin{array}{c}\Delta C_{p} \\
\left(\mathrm{~kJ} \mathrm{~mol}^{-1} \mathrm{~K}^{-1}\right)\end{array}$ \\
\hline \multirow{8}{*}{ wt/octa } & 10.1 & 1.02 & 1.6 & 31.4 & $35.7 \pm 0.7$ & 4.3 & \multirow{7}{*}{$-1.84 \pm 0.15$} \\
\hline & 10.4 & 1.03 & 1.7 & 31.3 & $43.8 \pm 0.5$ & 12.5 & \\
\hline & 25.0 & 1.00 & 4.5 & 30.5 & $61.4 \pm 0.9$ & 30.9 & \\
\hline & 25.2 & 0.98 & 3.9 & 30.9 & $69.5 \pm 0.6$ & 38.6 & \\
\hline & 30.0 & 0.97 & 10.6 & 28.8 & $83.0 \pm 1.7$ & 54.2 & \\
\hline & 32.1 & 1.00 & 10.9 & 29.0 & $82.9 \pm 3.1$ & 53.9 & \\
\hline & 40.0 & 1.08 & 22.0 & 27.9 & $85.3 \pm 2.6$ & 57.4 & \\
\hline & 9.2 & 1.05 & 0.9 & 32.7 & $41.4 \pm 0.5$ & 8.7 & \multirow{5}{*}{$-1.68 \pm 0.17$} \\
\hline \multirow{3}{*}{ D392N/octa } & 10.4 & 1.03 & 1.0 & 32.6 & $43.8 \pm 0.5$ & 11.2 & \\
\hline & 17.0 & 0.98 & 1.1 & 33.0 & $48.5 \pm 0.5$ & 15.5 & \\
\hline & 25.2 & 0.95 & 2.2 & 32.3 & $69.9 \pm 0.5$ & 37.3 & \\
\hline \multirow{5}{*}{ D392N/dodeca } & 30.0 & 0.98 & 3.2 & 31.9 & $68.6 \pm 1.0$ & 37.0 & \\
\hline & 40.0 & 0.93 & 9.0 & 30.2 & $94.9 \pm 1.2$ & 64.7 & \multirow{4}{*}{$-1.98 \pm 0.2$} \\
\hline & 15.0 & 0.97 & 0.65 & 34.1 & $50.2 \pm 0.5$ & 16.1 & \\
\hline & 25.0 & 0.92 & 1.2 & 33.8 & $66.9 \pm 0.5$ & 33.1 & \\
\hline & 40.0 & 0.89 & 6.6 & 31.0 & $98.1 \pm 5.5$ & 67.1 & \\
\hline
\end{tabular}

${ }^{a} \Delta G^{\circ}$ was calculated from $K_{\mathrm{D}}$, and the standard deviation was $<0.5 \mathrm{~kJ} \mathrm{~mol}^{-1} .{ }^{b}$ Standard deviations were directly obtained from the fitting routine for $\Delta H^{\circ}, n$, and $K_{\mathrm{A}}$. Standard deviations for $n$ and $K_{\mathrm{D}}$ were in no case higher than 4 and $10 \%$, respectively.

and present a detailed kinetic analysis of the binding reaction by stopped-flow fluorescence measurements. The results are discussed against the background of the crystal structure of the complex.

\section{MATERIALS AND METHODS}

Materials. Wild-type TSP $\Delta \mathrm{N}^{1}$ and TSP $\Delta \mathrm{N}$ D392N were expressed and purified as described previously $(24,64)$. The protein was stored in $40 \%$ saturated $\left(\mathrm{NH}_{4}\right)_{2} \mathrm{SO}_{4}$ and $50 \mathrm{mM}$ Tris/ $\mathrm{HCl}$ ( $\mathrm{pH} 8.0$ ). The concentration was determined using a specific absorption at $280 \mathrm{~nm}$ of $1.14 \mathrm{~cm}^{2} \mathrm{mg}^{-1}$.

$O$-Antigen fragments from Salmonella enteritidis SH1262 (serogroup $\mathrm{D}_{1}, O$-antigen 9,12 ) were purified and characterized as described previously (24).

Isothermal Titration Calorimetry. Proteins were dialyzed against $50 \mathrm{mM}$ sodium phosphate ( $\mathrm{pH}$ 7.0). The final dialysis buffer was used to dissolve defined quantities of oligosaccharides. Titrations were performed with a VP-ITC microcalorimeter (MicroCal, Inc., Northampton, MA) or an OMEGA microcalorimeter (MicroCal, Inc.). The stirred cell contained about $25 \mu \mathrm{M}$ tailspike subunits, and the syringe contained between 0.3 and $0.5 \mathrm{mM} O$-antigen fragments. A titration experiment consisted of 25 injections of 8 or $10 \mu \mathrm{L}$ with a $20 \mathrm{~s}$ duration and $230 \mathrm{~s}$ intervals each. In some experiments, an initial injection of $1 \mu \mathrm{L}$ was performed which was not used in data fitting. The titration data were corrected for small heat changes observed in control titrations of $O$-antigen fragments into buffer. Data were fit to a singlebinding site model using Origin (version 5.0, MicroCal, Inc.).

Stopped-Flow Measurements. An SX-18MV (Applied Photophysics, Leatherhead, U.K.) stopped-flow spectrofluorimeter was used for all kinetic measurements. The binding kinetics were followed by the change in fluorescence above $300 \mathrm{~nm}$ with excitation at $280 \mathrm{~nm}$ (5 nm bandwidth). All measurements were performed in $50 \mathrm{mM}$ sodium phosphate buffer (pH 7.0). Equal volumes of TSP $\Delta \mathrm{N}(20 \mu \mathrm{g} / \mathrm{mL}, 0.33$ $\mu \mathrm{M}$ binding sites) and $O$-antigen fragments $(1-200 \mu \mathrm{M})$

\footnotetext{
${ }^{1}$ Abbreviations: ASA, accessible surface area; ITC, isothermal titration calorimetry; TSP, tailspike protein; TSP $\Delta \mathrm{N}$, tailspike protein lacking the $\mathrm{N}$-terminal domain.
}

were mixed for each measurement. The temperature was controlled by a cryostat. For each concentration, at least 10 curves were averaged to calculate the apparent rate constant.

\section{RESULTS AND DISCUSSION}

The protein investigated here lacks the N-terminal headbinding domain. The shortened protein is fully functional in carbohydrate binding and hydrolysis (28). It is used here because it is readily accessible to crystallographic analysis, in contrast to the complete tailspike protein.

Isothermal Titration Calorimetry. A typical titration of TSP with $O$-antigen fragments is shown in panels A and B of Figure 2. The data of all measurements are summarized in Table 1. Titrations were performed with the wild-type protein and a mutant (D392N) with strongly reduced hydrolyzing activity. As the binding properties for this mutant are nearly identical to those of the wild type, this mutant could play an important role in elucidating the involvement of hydrolyzing activity in the infection process of the Salmonella cell. This mutant was also used in this study to assess the binding of tailspike protein to dodecasaccharide (three repeating units), which is significantly hydrolyzed by the wild-type protein during a titration experiment.

At all the temperatures that were investigated, there is a large negative binding enthalpy, but a strong dependence on temperature was also observed. The resulting $\Delta C_{p}$ appeared to be temperature-independent in the investigated temperature range (Figure 2C) and amounted to $-1.84 \pm 0.16 \mathrm{~kJ} \mathrm{~mol}^{-1}$ $\mathrm{K}^{-1}$ for octasaccharide binding to the wild-type protein and $-1.68 \pm 0.17$ and $-1.98 \pm 0.15 \mathrm{~kJ} \mathrm{~mol}^{-1} \mathrm{~K}^{-1}$ for octasaccharide and dodecasaccharide binding to D392N, respectively (refer to Table 1). The entropic contribution is unfavorable for binding in the investigated temperature range. There is almost perfect enthalpy-entropy compensation at different temperatures due to the large heat capacity change (29-33). Comparison of the dissociation constants with data obtained by fluorescence titration shows a reasonably good agreement (Figure 2D).

Possible reasons for a change in heat capacity upon binding are (1) conformational changes in protein or saccharide, (2) changes in ionization, (3) changes in the water network in 
Time (min)

$\mathrm{T}\left({ }^{\circ} \mathrm{C}\right)$

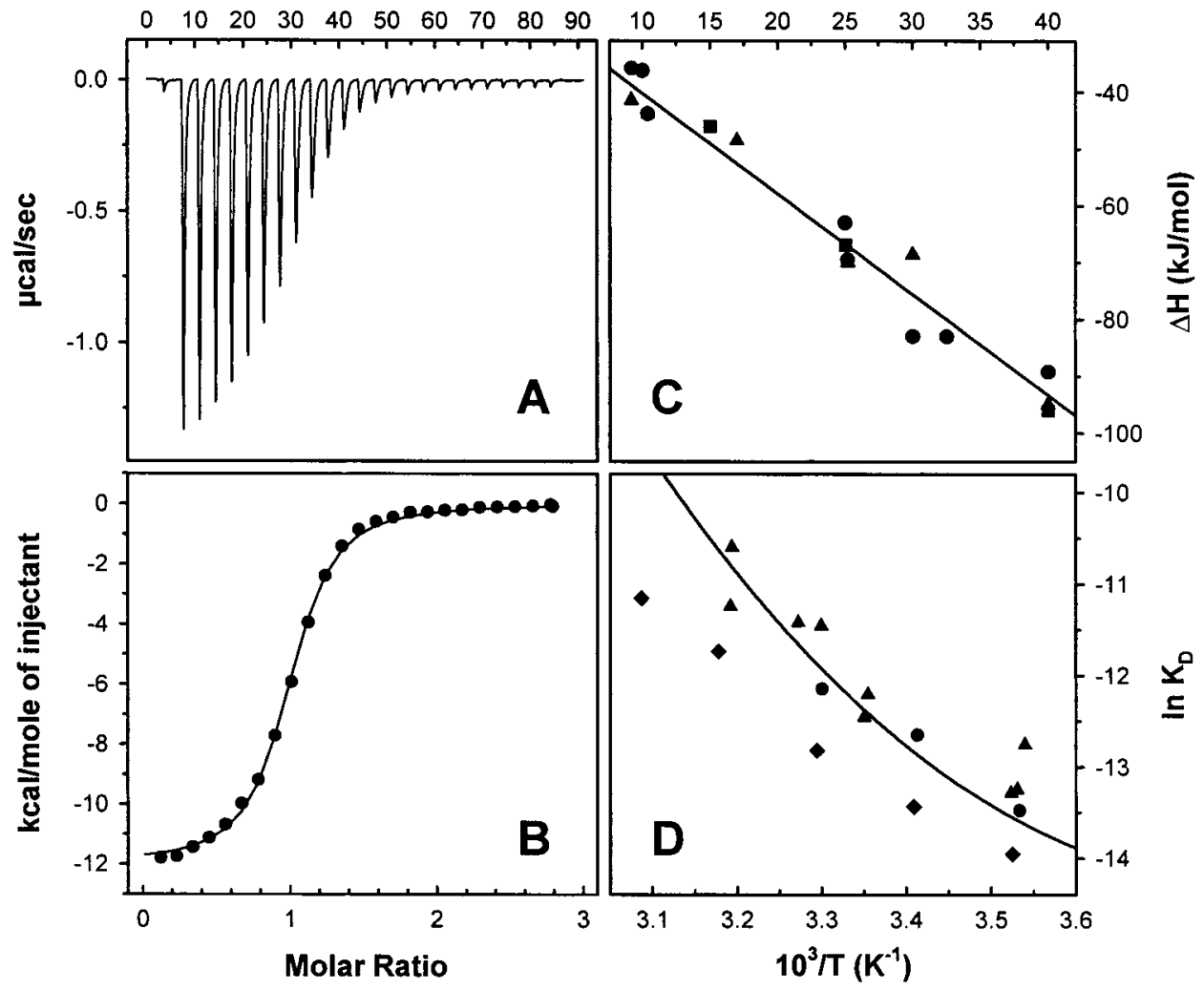

FIGURE 2: Results from ITC experiments. (A and B) Calorimetric titration of $25.6 \mu \mathrm{M}$ TSP $\Delta \mathrm{N}$ D392N with 0.5 mM dodecasaccharide at $15^{\circ} \mathrm{C}$. Panel A shows the measured heat change vs time and $\mathrm{B}$ the titration curve normalized to molar concentrations. The best fit of the data to a model with one set of binding sites obtained by nonlinear regression is shown as a solid line in the lower panel. (C) Dependence of $\Delta H_{\text {cal }}$ on the temperature [results for wild-type TSP $\Delta \mathrm{N}(\bullet)$ and TSP $\Delta \mathrm{N}$ D392N with octasaccharide $(\mathbf{\Delta})$ and TSP $\Delta \mathrm{N}$ D392N with

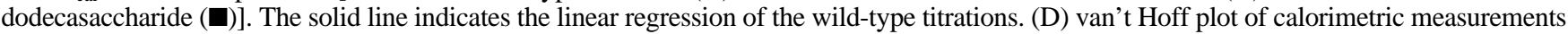
(A) compared with the results of fluorescence titrations $(\diamond)$ and kinetic measurements with octasaccharide $(\mathbf{O})$. The solid line shows a van't Hoff plot created with the results of a titration of wild-type TSP $\Delta \mathrm{N}$ with octasaccharide at $25^{\circ} \mathrm{C}$ and a $\Delta C_{p}$ of $1.84 \mathrm{~kJ}$ mol ${ }^{-1}$.

the binding site, and (4) release of water from hydrophobic surface upon binding. Recently, the change in the hydrogen bonding network from cooperatively ordered in the complex to floating in aqueous solution was proposed as a fifth reason (34). Ionization does not appear to play a major role, as the dissociation constant of octasaccharide is only slightly influenced by different buffers (Tris or phosphate) and by different ionic strengths measured from 0 to $200 \mathrm{mM}$ (35), and isothermal titration calorimetric experiments in Tris buffer showed no difference to phosphate buffer (data not shown). Comparison of the crystal structures shows that the conformation of the protein does not change from the free to the saccharide-bound form (27). The only difference is a lower temperature factor of some residues in the binding site, which is often seen in protein-ligand complexes. The conformation of the saccharide is fixed upon binding, whereas a distribution of conformations in solution was found by NMR methods (36). In Table 2 , the conformation in the complex is compared to the most relaxed conformation in solution determined by molecular modeling and NMR (3638). Although there might be differences in the torsion angles $\Psi$ of the Gal-Man glycosidic bonds, the bound conformation is close to the minimum energy conformation of the $O$-antigen oligosaccharide. Freezing this conformation upon binding is not expected to give rise to a large enthalpy change, but may contribute to the unfavorable binding entropy and to the heat capacity change.
Table 2: Torsion Angles (Degrees) of Glycosidic Bonds in $O$-Antigen ${ }^{a}$

\begin{tabular}{lrrrrrr}
\hline & $\begin{array}{c}\Phi \\
\text { (bound) }^{b}\end{array}$ & $\begin{array}{c}\Phi \\
(\text { free })^{c}\end{array}$ & $\begin{array}{c}\Phi \\
\text { free) }^{d}\end{array}$ & $\begin{array}{c}\Psi \\
\text { (bound) }^{b}\end{array}$ & $\begin{array}{c}\Psi \\
(\text { free })^{c}\end{array}$ & $\begin{array}{c}\Psi \\
\text { free) }^{d}\end{array}$ \\
\hline S1Gal-S2Man & -47.4 & -46 & -35 & 30.7 & -19 & 29 \\
S3Tyv-S2Man & -53.5 & -48 & -51 & 10.0 & -8 & 7 \\
S2Man-S4Rha & -25.7 & -39 & & -7.3 & -13 & \\
S4Rha-S5Gal & 55.2 & 50 & & 13.1 & 6 & \\
S5Gal-S6Man & -31.7 & -46 & -35 & 34.7 & -19 & 29 \\
S7Tyv-S6Man & -50.4 & -48 & -51 & 12.0 & -8 & 7 \\
S6Man-S8Rha & -41.0 & -39 & & 10.6 & -13 & \\
\hline
\end{tabular}

${ }^{a} \Phi$ and $\Psi$ refer to the $\mathrm{H} 1-\mathrm{C} 1-\mathrm{O} 1-\mathrm{C} x$ and $\mathrm{C} 1-\mathrm{O} 1-\mathrm{C} x-\mathrm{H} x$ torsion angles, respectively, where $x$ is the linkage position of the adjacent sugar residue. ${ }^{b}$ From the crystal structure of PDB entry 1TYU. ${ }^{c}$ Taken from refs 37 and 38. ${ }^{d}$ Taken from ref 36 . The values in the table are either the first or second minimum given in the reference which are different by only $2 \mathrm{~kJ} \mathrm{~mol}^{-1}$.

Traditionally, a large negative $\Delta C_{p}$ is taken as a sign of hydrophobic interactions (39-41), i.e., the release of water from hydrophobic surfaces upon binding, although large changes in heat capacity could also arise due to changes in the hydrogen bonding network (34). The difference in solvent-accessible surface area due to complex formation ( $\triangle \mathrm{ASA}$ ) between TSP and $O$-antigen measures $1260 \AA^{2}$, and about $60 \%$ of the buried surface is nonpolar.

For protein folding reactions and protein-protein interactions, both the binding enthalpy and the change in heat capacity were successfully predicted by using the empirical 
Table 3: Kinetics of Binding of $O$-Antigen Fragments to Wild-Type TSP $\Delta \mathrm{N}$

\begin{tabular}{|c|c|c|c|c|c|c|}
\hline & \multicolumn{3}{|c|}{ octasaccharide } & \multicolumn{3}{|c|}{ dodecasaccharide } \\
\hline & $k_{\mathrm{on}}\left(\times 10^{5} \mathrm{M}^{-1} \mathrm{~s}^{-1}\right)$ & $k_{\text {off }}\left(\mathrm{s}^{-1}\right)$ & $K_{\mathrm{D}}{ }^{a}(\mu \mathrm{M})$ & $k_{\mathrm{on}}\left(\times 10^{5} \mathrm{M}^{-1} \mathrm{~s}^{-1}\right)$ & $k_{\text {off }}\left(\mathrm{s}^{-1}\right)$ & $K_{\mathrm{D}}^{a}(\mu \mathrm{M})$ \\
\hline $10^{\circ} \mathrm{C}$ & $1.8 \pm 0.1$ & $0.25 \pm 0.02$ & 1.4 & $1.0 \pm 0.08$ & $0.17 \pm 0.02$ & 1.7 \\
\hline $20^{\circ} \mathrm{C}$ & $2.6 \pm 0.13$ & $0.85 \pm 0.04$ & 3.2 & $2.2 \pm 0.15$ & $1.0 \pm 0.06$ & 4.5 \\
\hline $30^{\circ} \mathrm{C}$ & $7.1 \pm 0.6$ & $3.8 \pm 0.2$ & 5.3 & $3.7 \pm 0.32$ & $2.1 \pm 0.17$ & 5.7 \\
\hline$E_{\mathrm{a}}\left(\mathrm{kJ} \mathrm{mol}^{-1}\right)^{b}$ & $50 \pm 15$ & $100 \pm 8$ & & $47 \pm 10$ & $90 \pm 8$ & \\
\hline
\end{tabular}

${ }^{a}$ Dissociation constants calculated from kinetic data $\left(K_{\mathrm{D}}=k_{\mathrm{off}} / k_{\mathrm{on}}\right) \cdot{ }^{b}$ Arrhenius activation energies were calculated from the corresponding rate constants using the slopes $m$ of linear regressions and the relation $m=-E_{\mathrm{a}} / R$. Errors of the activation energies are estimated from the standard deviation of the single rate constants.

formula $\Delta H=\Delta h_{\mathrm{pol}} \Delta \mathrm{ASA}_{\mathrm{pol}}+\Delta h_{\mathrm{ap}} \Delta \mathrm{ASA}_{\mathrm{ap}}$ and $\Delta C_{p}=$ $\Delta c_{\mathrm{p}, \mathrm{ap}} \Delta \mathrm{ASA}_{\mathrm{ap}}+\Delta c_{\mathrm{p}, \mathrm{pol}} \Delta \mathrm{ASA}_{\mathrm{pol}}$, where the parameters are derived from available data sets $(1,40,42)$. The same was done recently for the interaction of small oligosaccharides with lectins (15). Using the parameters $\Delta h_{\mathrm{pol}}$ and $\Delta h_{\mathrm{ap}}$ derived from protein folding reactions, $\Delta H^{\circ}$ at $25^{\circ} \mathrm{C}$ would amount to about $-45 \mathrm{~kJ} \mathrm{~mol}^{-1}$, whereas the parameter set introduced recently for lectins results in a value of $-79 \mathrm{~kJ}$ $\mathrm{mol}^{-1}$. The latter result compares well with the measured value of about $-67 \mathrm{~kJ} \mathrm{~mol}^{-1}$.

Interestingly, the number of direct hydrogen bonds in the $O$-antigen tailspike complex $\left(1.8\right.$ per $\left.100 \AA^{2} \Delta \mathrm{ASA}_{\text {pol }}\right)$ is much lower than the average number of 3.5 per $100 \AA^{2}$ $\triangle \mathrm{ASA}_{\mathrm{pol}}$ in the lectin complex data set of Garcia-Hernandez and Hernandez-Arana (15). These authors argued that the slightly higher number of 3.5 hydrogen bonds per $100 \AA^{2}$ $\triangle \mathrm{ASA}_{\mathrm{pol}}$ in lectin saccharide complexes compared to 3.0 per $100 \AA^{2} \Delta \mathrm{ASA}_{\mathrm{pol}}$ in proteins could account for the more than 2 -fold difference in the parameter $\Delta h_{\text {pol }}$ they had to use to describe the data set. Counting indirect, water-mediated hydrogen bonds in the TSP octasaccharide complex brings the number up to 3.0 per $100 \AA^{2} \Delta \mathrm{ASA}_{\text {pol }}$, which still is only the number found for proteins. Thus, direct hydrogen bonds might not be that important. Instead, as stated by Lemieux and co-workers, the solvent release from polyamphiphilic surfaces could supply a large part of the enthalpy $(20,21,23)$. It seems plausible therefore that different parameter sets have to be established whenever different polyamphiphilic surfaces are involved in binding reactions as in protein-protein and protein-carbohydrate interactions.

Estimation of the change in heat capacity with parameters derived from protein folding reactions $(40,42)$ and also successfully used for protein-protein interactions $(l)$ resulted in values of around $-0.9 \mathrm{~kJ} \mathrm{~mol}^{-1} \mathrm{~K}^{-1}$ which is only half of the measured value of $-1.8 \mathrm{~kJ} \mathrm{~mol}^{-1} \mathrm{~K}^{-1}$. This might be due to the fact that hydroxyl groups are behaving surprisingly hydrophobically in terms of their contribution to the heat capacity change (43). If the hydroxyl groups are judged to be nonpolar (of the $1260 \AA^{2} \triangle \mathrm{ASA}$, about $88 \%$ are nonpolar), the calculated heat capacity change resulted in values of around $1.7 \mathrm{~kJ} \mathrm{~mol}^{-1} \mathrm{~K}^{-1}$, which seems to be in good agreement with the measured value. In contrast, protein folding parameter sets were successfully used to predict the change in heat capacity for some complexes with smaller saccharides (16) without taking hydroxyl groups as hydrophobic surface. Whether it is necessary to define new parameter sets for the binding of large carbohydrates to proteins remains to be seen when more thermodynamic and structural data on such interactions become available and when the role of hydroxyl groups becomes clearer.
Most experimentally determined heat capacity changes upon binding of saccharides to proteins range from large negative (44) to near zero (45), as was also found for most interactions of proteins with small ligands (46). Some positive heat capacity changes (47) and even a strong dependence of $\Delta C_{p}$ on temperature have been reported (31). However, these systems are complicated by conformational changes in the protein from which a large part of the heat capacity change may originate.

van't Hoff enthalpies calculated from the binding constants determined by ITC may be compared to the van't Hoff enthalpies previously determined by fluorescence titrations at different temperatures (24), and to the van't Hoff enthalpies calculated from the binding equilibrium constants resulting from the stopped-flow kinetic measurements (compare below and Table 3). All van't Hoff enthalpies (Figure 2D) are in the same range as the calorimetric enthalpy $\Delta H_{\text {cal }}$, and the $\Delta H_{\mathrm{vH}} / \Delta H_{\text {cal }}$ ratios are between 0.7 and 1.1, which is in reasonable agreement with the expected value of 1.0.

For the antibody Se155-4 which also recognizes $O$-antigen from serogroup B Salmonella, a similar free energy of binding was found (31), but in this system, both the enthalpy and the entropy are driving the reaction at room temperature (11). This might be due to the high level of aromatic side chains in the binding region of this antibody contributing about $130 \AA^{2}$ to $\triangle \mathrm{ASA}$ ( $50 \%$ of $\triangle \mathrm{ASA}$ on the protein side) $(48,49)$. In TSP, the aromatic side chains of Trp365 and Trp391 are involved in the binding of octasaccharide but their $\triangle$ ASAs only contribute $90 \AA^{2}(15 \%$ of $\triangle$ ASA on the protein side). Both the antibody Se155-4 and TSP are highly specific for Salmonella $O$-antigen, but whereas the antibody mainly recognizes the 3,6-dideoxyhexose side chain (abequose) and also the adjacent monosaccharides galactose and mannose $(11,48,49)$, the specificity of TSP is mainly reached by spreading the binding contacts over at least six monosaccharides of the octasaccharide (two repeating units) and TSP can bind the $O$-antigen regardless of the configuration of the 3,6-dideoxyhexose side chain $(24,27)$. Still the 3,6-dideoxyhexose side chain contributes an important part of the free energy of binding since no binding was detected in saccharide fragments without side chains (U. Baxa and R. Seckler, unpublished results; 50).

Binding Kinetics. The intrinsic tryptophan fluorescence of TSP decreases about 20\% upon saccharide binding (24). Using this effect, the kinetics of octasaccharide and dodecasaccharide binding were measured over a temperature range from 10 to $30{ }^{\circ} \mathrm{C}$. The decrease in tryptophan fluorescence upon mixing TSP and saccharide solution was followed. A representative stopped-flow fluorescence trace is shown in Figure 3A. Experiments were performed under pseudo-first- 


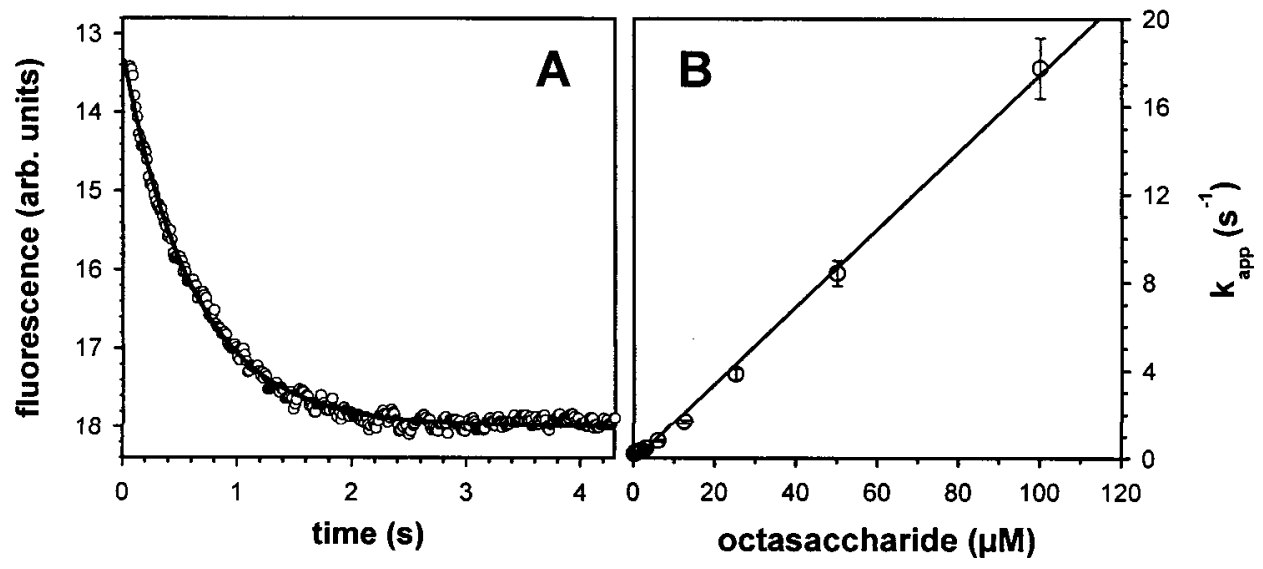

FIGURE 3: Results from stopped-flow experiments. (A) Trace of the change in the intrinsic tryptophan fluorescence due to the binding of $0.17 \mu \mathrm{M}$ wild-type TSP $\Delta \mathrm{N}$ with $6 \mu \mathrm{M}$ octasaccharide at $20^{\circ} \mathrm{C}(\mathrm{O})$. The solid line shows the best fit of the data with a monoexponential model. (B) Saccharide concentration dependence of the apparent rate of complex formation measured at $10^{\circ} \mathrm{C}$. The slope of the linear regression gives the association rate constant $\left(1.8 \times 10^{6} \mathrm{M}^{-1} \mathrm{~s}^{-1}\right)$, and the ordinate intercept yields the dissociation rate constant $\left(0.25 \mathrm{~s}^{-1}\right)$. Error bars indicate the standard deviation of at least 10 measurements.

order conditions (excess oligosaccharide), and the constant $k_{\text {app }}$ for a first-order reaction was determined. Plots of $k_{\text {app }}$ versus ligand concentration resulted in straight lines (e.g., Figure 3B), and the data could be interpreted as a singlestep reaction without kinetic intermediates $(\mathrm{P}+\mathrm{S} \rightleftharpoons \mathrm{PS})$. The values of $k_{\text {on }}$ and $k_{\text {off }}$ were determined from the slope and intercept of the linear plots. All data are summarized in Table 3. The equilibrium dissociation constants calculated from the $k_{\text {on }}$ and $k_{\text {off }}$ values at different temperatures compare well with the dissociation constants from isothermal calorimetry and fluorescence titrations (Figure 2C). The activation energies were obtained from linear Arrhenius plots $\left(r^{2}\right.$ $=0.92-0.99$ ). These can only give a rough estimate at the middle temperature of $20^{\circ} \mathrm{C}$, because Arrhenius plots cannot be expected to be linear over a larger temperature range due to the large heat capacity change. Within the experimental error, the activation energies are equal for both octasaccharide and dodecasaccharide and amount to about $50 \pm 15$ and $100 \pm 10 \mathrm{~kJ} \mathrm{~mol}^{-1}$ for the association and dissociation reactions, respectively (Table 3 ). These relatively high activation energies indicate mainly enthalpic barriers, possibly caused by the desolvation of the protein and saccharide necessary prior to association, and again emphasizing the role of the solvent in this reaction. Having estimates for both dissociation and association activation energy allows us to calculate the enthalpy change of the binding reaction at $20{ }^{\circ} \mathrm{C}$. With about $-50 \pm 10 \mathrm{~kJ} \mathrm{~mol}^{-1}$, this is in good agreement with the calorimetrically determined enthalpy of $-58 \mathrm{~kJ} \mathrm{~mol}^{-1}$ at $20^{\circ} \mathrm{C}$ (Table 1 and linear fit in Figure $2 \mathrm{C}$ ).

The observed association rates are in a range observed for many other protein-saccharide systems, even when much smaller oligo- and monosaccharides are involved (51-53). For an association reaction requiring rotational alignment and specific interactions of two macromolecules, the rate estimated theoretically lies between $0.5 \times 10^{6}$ and $5 \times 10^{6} \mathrm{~s}^{-1}$ $\mathrm{M}^{-1}(54)$. A faster rate is often observed when electrostatic interactions accelerate the reaction $(55,56)$. This obviously does not apply here, where neutral carbohydrates are involved. The flexibility of oligosaccharides may also slow the reaction, as a special conformation of the saccharides might need to be picked out for a productive collision. In summary, the measured association rates of TSP and octasaccharide appear to be reasonable. Quantitative model- ing with Brownian dynamics simulation, as was done for protein-protein interactions (54), would be difficult here due to the flexibility of the saccharide.

Fluorescence change is routinely used for kinetic measurements of carbohydrate binding to proteins (57). Either the intrinsic protein fluorescence, as in this study, or a fluorophor-labeled saccharide can be used $(58,59)$. Another possible method, surface plasmon resonance, was used to determine the binding kinetics of antibody Se155-4 and a single chain fragment derived from this to immobilized $O$-antigen polysaccharide and trisaccharide $(60,61)$. The association rates were around $5 \times 10^{4} \mathrm{M}^{-1} \mathrm{~s}^{-1}$, but dimeric $\mathrm{scFv}$ fragments had association rates about 5-fold higher (62), indicating that not every collision is productive and that two binding sites on one molecule can increase the probability for a productive binding. For monomeric scFv fragments, the rates were around $0.1 \mathrm{~s}^{-1}$, and as expected, dissociation is much slower for whole antibody and dimeric $\mathrm{scFv}$ fragments due to bivalent binding (62). Both dissociation and association are about 10 -fold slower in this system than for the TSP octasaccharide system (Table 3), showing that saccharide binding to TSP is highly dynamic.

\section{CONCLUSIONS}

The binding of P22 TSP to $O$-antigen fragments is an enthalpically driven reaction at room temperature, but connected with a large negative change in heat capacity. This large heat capacity change is largely due to hydrophobic interaction and water reorganization, because the protein conformation does not change upon saccharide binding and the structure of the bound saccharide is close to the minimum energy conformation in solution. Predicting the change in heat capacity and the binding enthalpy from the change in accessible surface area using empirical parameter sets yields satisfactory results only for the binding enthalpy but underestimates the change in heat capacity.

The important role of solvent in this binding process is also supported by the large enthalpic barriers in both the association and dissociation reactions. The association rate lies in a similar range as described for the binding of other carbohydrates to proteins. As in this system no hint of an association intermediate was found, the association velocity 
seems to be governed by the need for rotational alignment and the flexibility of the saccharide.

\section{ACKNOWLEDGMENT}

We thank Dr. J. Buchner for access to the stopped-flow instrument.

\section{REFERENCES}

1. Baker, B. M., and Murphy, K. P. (1998) Methods Enzymol. 295, 294-315.

2. Murphy, K. P. (1999) Med. Res. Rev. 19, 333-9.

3. Hilser, V. J., Gomez, J., and Freire, E. (1996) Proteins 26, $123-33$.

4. Luque, I., and Freire, E. (1998) Methods Enzymol. 295, 10027.

5. Dam, T. K., Roy, R., Das, S. K., Oscarson, S., and Brewer, C. F. (2000) J. Biol. Chem. 275, 14223-30.

6. Dam, T. K., Cavada, B. S., Grangeiro, T. B., Santos, C. F., Ceccatto, V. M., de Sousa, F. A., Oscarson, S., and Brewer, C. F. (2000) J. Biol. Chem. 275, 16119-26.

7. Thomson, J., Liu, Y., Sturtevant, J. M., and Quiocho, F. A. (1998) Biophys. Chem. 70, 101-8.

8. Rozwarski, D. A., Swami, B. M., Brewer, C. F., and Sacchettini, J. C. (1998) J. Biol. Chem. 273, 32818-25.

9. Dam, T. K., Oscarson, S., and Brewer, C. F. (1998) J. Biol. Chem. 273, 32812-7.

10. Mandal, D. K., Kishore, N., and Brewer, C. F. (1994) Biochemistry 33, 1149-56.

11. Bundle, D. R., Eichler, E., Gidney, M. A., Meldal, M., Ragauskas, A., Sigurskjold, B. W., Sinnott, B., Watson, D. C., Yaguchi, M., and Young, N. M. (1994) Biochemistry 33, $5172-82$.

12. Schwarz, F. P., Puri, K. D., Bhat, R. G., and Surolia, A. (1993) J. Biol. Chem. 268, 7668-77.

13. Williams, B. A., Chervenak, M. C., and Toone, E. J. (1992) J. Biol. Chem. 267, 22907-11.

14. Bains, G., Lee, R. T., Lee, Y. C., and Freire, E. (1992) Biochemistry 31, 12624-8.

15. Garcia-Hernandez, E., and Hernandez-Arana, A. (1999) Protein Sci. 8, 1075-86.

16. Garcia-Hernandez, E., Zubillaga, R. A., Rojo-Dominguez, A., Rodriguez-Romero, A., and Hernandez-Arana, A. (1997) Proteins 29, 467-77.

17. Toone, E. J. (1994) Curr. Opin. Struct. Biol. 4, 719-28.

18. Bundle, D. R., and Young, N. M. (1992) Curr. Opin. Struct. Biol. 2, 666-73.

19. Lemieux, R. U., Delbaere, L. T. J., Beierbeck, H., and Spohr, U. (1991) Ciba Found. Symp. 158, 231-48.

20. Chervenak, M. C., and Toone, E. J. (1994) J. Am. Chem. Soc. 116, 10533-9.

21. Lemieux, R. U. (1996) Acc. Chem. Res. 29, 373-80.

22. Beierbeck, H., Delbaere, L. T. J., Vandonselaar, M., and Lemieux, R. U. (1994) Can. J. Chem. 72, 463-70.

23. Lemieux, R. U., Du, M. H., and Spohr, U. (1994) J. Am. Chem. Soc. 116, 9803-4.

24. Baxa, U., Steinbacher, S., Miller, S., Weintraub, A., Huber, R., and Seckler, R. (1996) Biophys. J. 71, 2040-8.

25. Steinbacher, S., Miller, S., Baxa, U., Budisa, N., Weintraub, A., Seckler, R., and Huber, R. (1997) J. Mol. Biol. 267, 86580.

26. Steinbacher, S., Seckler, R., Miller, S., Steipe, B., Huber, R., and Reinemer, P. (1994) Science 265, 383-6.

27. Steinbacher, S., Baxa, U., Miller, S., Weintraub, A., Seckler, R., and Huber, R. (1996) Proc. Natl. Acad. Sci. U.S.A. 93, 10584-8

28. Danner, M., Fuchs, A., Miller, S., and Seckler, R. (1993) Eur. J. Biochem. 215, 653-61.

29. Cooper, A. (1999) Curr. Opin. Chem. Biol. 3, 557-63.

30. McPhail, D., and Cooper, A. (1997) J. Chem. Soc., Faraday Trans. 93, 2283-9.

31. Sigurskjold, B. W., and Bundle, D. R. (1992) J. Biol. Chem. $267,8371-6$.
32. Tame, J. R. H., O'Brian, R., and Ladbury, J. E. (1998) in Biocalorimetry (Ladbury, J. E., and Chowdhry, B. Z., Eds.) pp 27-38, John Wiley \& Sons, Chichester, U.K.

33. Ha, J. H., Spolar, R. S., and Record, M. T., Jr. (1989) J. Mol. Biol. 209, 801-16.

34. Cooper, A. (2000) Biophys. Chem. 85, 25-39.

35. Baxa, U. (1998) D.Sc. Thesis, University of Regensburg, Regensburg, Germany.

36. Bundle, D. R., Baumann, H., Brisson, J. R., Gagne, S. M., Zdanov, A., and Cygler, M. (1994) Biochemistry 33, 518392.

37. Bock, K., Meldal, M., Bundle, D. R., Iversen, T., Pinto, B. M., Garegg, P. J., Kvanstrom, I., Norberg, T., Lindberg, A. A., and Svenson, S. B. (1984) Carbohydr. Res. 130, 35-53.

38. Bock, K., Meldal, M., Bundle, D. R., Iversen, T., Garegg, P. J., Norberg, T., Lindberg, A. A., and Svenson, S. B. (1984) Carbohydr. Res. 130, 23-34.

39. Livingstone, J. R., Spolar, R. S., and Record, M. T., Jr. (1991) Biochemistry 30, 4237-44.

40. Spolar, R. S., Livingstone, J. R., and Record, M. T., Jr. (1992) Biochemistry 31, 3947-55.

41. Privalov, P. L., and Makhatadze, G. I. (1992) J. Mol. Biol. 224, 715-23.

42. Murphy, K. P., and Gill, S. J. (1991) J. Mol. Biol. 222, 699709.

43. Habermann, S. M., and Murphy, K. P. (1996) Protein Sci. 5, 1229-39.

44. Fukada, H., Sturtevant, J. M., and Quiocho, F. A. (1983) J. Biol. Chem. 258, 13193-8.

45. St. Hilaire, P. M., Boyd, M. K., and Toone, E. J. (1994) Biochemistry 33, 14452-63.

46. Wiesinger, H., and Hinz, H. J. (1986) in Thermodynamic data for biochemistry and biotechnology (Hinz, H. J., Ed.) pp 21126, Springer-Verlag, Berlin.

47. Zidovetzki, R., Blatt, Y., Schepers, G., and Pecht, I. (1988) Mol. Immunol. 25, 379-83.

48. Cygler, M., Rose, D. R., and Bundle, D. R. (1991) Science 253, 442-5.

49. Zdanov, A., Li, Y., Bundle, D. R., Deng, S. J., MacKenzie, C. R., Narang, S. A., Young, N. M., and Cygler, M. (1994) Proc. Natl. Acad. Sci. U.S.A. 91, 6423-7.

50. Eriksson, U., Svenson, S. B., Lonngren, J., and Lindberg, A. A. (1979) J. Gen. Virol. 43, 503-11.

51. De Boeck, H., Lis, H., van Tilbeurgh, H., Sharon, N., and Loontiens, F. G. (1984) J. Biol. Chem. 259, 7067-74.

52. Krishna Sastry, M. V., Swamy, M. J., and Surolia, A. (1988) J. Biol. Chem. 263, 14826-31.

53. Miller, D. M., Olson, J. S., Pflugrath, J. W., and Quiocho, F. A. (1983) J. Biol. Chem. 258, 13665-72.

54. Northrup, S. H., and Erickson, H. P. (1992) Proc. Natl. Acad. Sci. U.S.A. 89, 3338-42.

55. Elcock, A. H., Gabdoulline, R. R., Wade, R. C., and McCammon, J. A. (1999) J. Mol. Biol. 291, 149-62.

56. Gabdoulline, R. R., and Wade, R. C. (1997) Biophys. J. 72, 1917-29.

57. Lee, Y. C. (1997) J. Biochem. 121, 818-25.

58. Kunikata, T., Yamano, H., Nagamura, T., and Nitta, Y. (1992) J. Biochem. 112, 421-5.

59. Sanadi, A. R., and Surolia, A. (1994) J. Biol. Chem. 269 , 5072-7.

60. Deng, S. J., MacKenzie, C. R., Sadowska, J., Michniewicz, J., Young, N. M., Bundle, D. R., and Narang, S. A. (1994) J. Biol. Chem. 269, 9533-8.

61. Deng, S. J., MacKenzie, C. R., Hirama, T., Brousseau, R., Lowary, T. L., Young, N. M., Bundle, D. R., and Narang, S. A. (1995) Proc. Natl. Acad. Sci. U.S.A. 92, 4992-6.

62. MacKenzie, C. R., Hirama, T., Deng, S. J., Bundle, D. R., Narang, S. A., and Young, N. M. (1996) J. Biol. Chem. 271, 1527-33.

63. Wallace, A. C., Laskowski, R. A., and Thornton, J. M. (1995) Protein Eng. 8, 127-34.

64. Miller, S., Schuler, B., and Seckler, R. (1998) Protein Sci. 7, 2223-32.

BI0020426 